\title{
Does the ileocolonic junction differentiate between solids and liquids?
}

\author{
J Hammer, M Camilleri, S F Phillips, A Aggarwal, A M Haddad $†$
}

\begin{abstract}
Previous observations from our laboratory have suggested that colonic filling from the ileum is characterised by a series of bolus movements. The present experiments were designed to test the hypothesis that bolus transit of ileal contents into the colon would not distinguish between solids and liquids. After a manometric infusion assembly was positioned by mouth into the ileum of 13 healthy volunteers, a mixture of nutrients (75 kcal), incorporating a solid phase radiolabel ("II In labelled resin pellets) and a liquid phase marker ( ${ }^{99} \mathrm{~m}$ Tc-DTPA), was infused into the ileum. Transit of both labels from the ileum to colon was quantified scintigraphically and ileal motility was also recorded. When markers were infused into the proximal ileum, $100 \mathrm{~cm}$ proximal to the ileocolonic junction (six), there were clear cut examples of discriminant transit, when liquids moved more rapidly from the small to the large bowel than did solids. When isotopes were instilled into the distal ileum, less than $50 \mathrm{~cm}$ from the ileocolonic junction, no separate transit of the solid and liquid phases was observed. No specific motor pattern of the ileum was regularly associated with bolus filling of the colon. These results support the hypothesis that the distal ileum can discriminate between solids and liquids but that the ileocecal junction cannot. (Gut 1993; 34: 222-226)
\end{abstract}

The differential transit of liquids and solids along the gastrointestinal tract has been examined most extensively at the level of the stomach; the antroduodenal junction regularly separates liquids from solids.' ${ }^{1}$ Thus, the entry of liquids into the duodenum can be described by an exponential function, but solids are initially retained by the stomach ('lag period'), triturated and then passed into the duodenum in a linear fashion. ' Despite much study, the precise motor mechanisms responsible for the gastroduodenal discrimination of solids from liquids are still uncertain. On the other hand, chyme moves through the small intestine discontinuously ${ }^{23}$; bursts of rapid flow alternate with periods of slower transit. Observations in dogs ${ }^{4}$ suggest that liquids move along the small bowel faster than solids, whereas a careful study in $\operatorname{man}^{5}$ found that, after correction for different rates of gastric emptying, the transit times to the caecum for solids and liquids were similar.

It is unknown whether the ileocolonic junction separates solids from liquids. In $\operatorname{dogs}^{6}$ and man, the transit of liquids and solids from ileum to colon was largely intermittent, occurring as a series of bolus movements separated by plateaus when little or no colonic filling occurred. Moreover, these patterns of bolus flow in health were preserved in some pathological conditions. ${ }^{8}$ Because many of the motor patterns of the ileum are thought to be peristaltic and therefore propulsive,${ }^{910}$ the colon appears to fill mainly by discrete boluses. ${ }^{78}$ Our hypothesis was that the ileocolonic junction would not distinguish between solids and liquids. Thus, we proposed that the ileum would empty is enteric contents, liquids and solids, together as a series of boluses.

To simultaneously measure the transit of solids and liquids across the human ileocolonic junction, we developed a method whereby both physical phases were introduced together into the ileum. Subsequent transit of liquids and solids could be quantified independently by scintigraphy. We also attempted to relate bolus transfer to patterns of ileal motility, by recording ileal motility concurrently.

\section{Methods}

\section{VOLUNTEERS}

Thirteen healthy volunteers, seven men and six women, aged 21-49 years, participated in the study after giving written informed consent to a protocol that had been approved previously by the Institutional Review Board and Radiation Safety Committee of Mayo Clinic. None complained of gastrointestinal symptoms, had previously undergone abdominal surgery other than appendectomy or was taking medication known to alter intestinal transit. Women were required to have a negative pregnancy test less than 48 hours before their participation in the study.

INTUBATION SYSTEM AND MOTILITY RECORDINGS An eight lumen tube was constructed by bonding together two triple lumen tubes (ID $0.78 \mathrm{~mm}$, Dural Plastics, Dural 2158, New South Wales, Australia) and two single lumen tubes. The single lumen tube for infusion of the 'meal' into the small bowel had an internal diameter of 1.6 $\mathrm{mm}$, the other single lumen tube (id $1 \mathrm{~mm}$ ) was radioopaque; it was used to locate the tube fluoroscopically and inflate a balloon that surrounded a terminal mercury weight." The triple lumen tubes were used for low compliance perfusion manometry of the small bowel. ${ }^{1 !}$

Subjects presented for intubation after fasting overnight. The tube was passed by mouth and, as soon as its tip reached the descending duodenum, the balloon was inflated to speed passage of the tube. The balloon was deflated when it was close to the ileocolonic junction. Figure 1 shows the anatomical locations of infusion sites and 
Site of infusion and motility ports

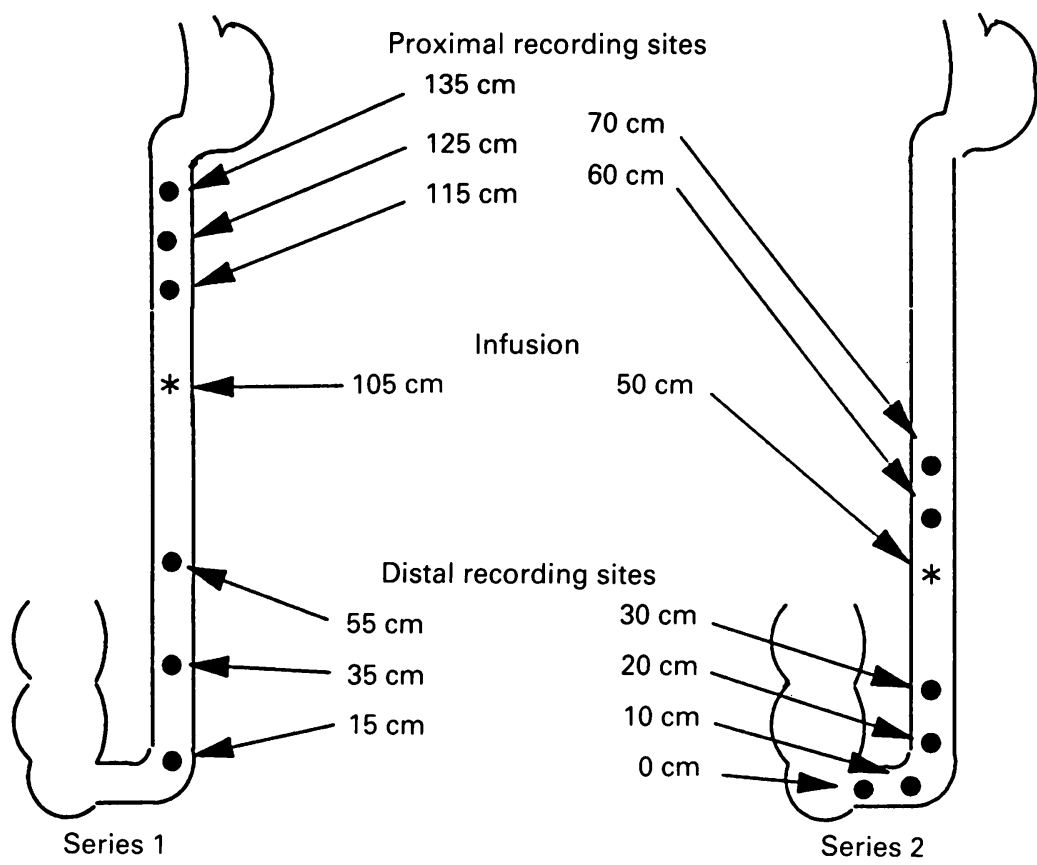

Figure 1: Anatomical localisation of infusion/motility assemblies in the two series of experiments.
Denver, CO) multichannel pen recorder (chart speed $2.5 \mathrm{~cm} / \mathrm{min}$ ) and transferred to a VAX 750 computer for further analysis. Manometric recordings began as soon as the assembly was in place; fasting recordings of motility lasted for 60 minutes before the isotopic 'meal' was instilled into the small bowel. Fasting motor patterns were normal in all volunteers.

TRANSIT OF SOLIDS AND LIQUIDS

A radiolabelled solid liquid 'meal' $(100 \mathrm{ml})$ was infused into the small bowel through the infusion lumen, at $2 \mathrm{ml} / \mathrm{min}$. It consisted of $4 \mathrm{~g}$ dextrose, $12 \mathrm{~g}$ rice starch, $1 \mathrm{~g}$ casein hydrolysate $(75 \mathrm{kcal})$ and $3 \mathrm{~g} \mathrm{Veegum}^{\bullet}$ (aluminium magnesium silicate). The infusate also contained a solid (7) radiolabel ( $1 \mathrm{~mm}$ Amberlite 120 IRP resin pellets labelled with $100 \mu \mathrm{Ci}{ }^{~}{ }^{\prime \prime} I n \mathrm{Cl}_{3}$ ) and an isotope in the liquid phase $\left.{ }^{99 m} \mathrm{Tc}-\mathrm{DTPA} ; 500 \mu \mathrm{Ci}\right)$ in 10 $\mathrm{ml}$ saline, stabilised with $1 \% \mathrm{w} / \mathrm{v}$ bovine serum albumen. Veegum thickened the meal and prevented sedimentation of the resin pellets during infusion. The osmolality was $300 \mathrm{mOsmol} / \mathrm{kg}$, and the $\mathrm{pH}$ was adjusted to 6.4 with $1.0 \mathrm{~N} \mathrm{HCl}$. After the isotope mixture was instilled, scintigraphic imaging began.

Dynamic imaging (duration of frames: $1 \mathrm{~min}$; 60 frames/hour) was performed with an anterior, large field of view gamma camera with a medium energy, parallel hole collimator (GE Starcam, Milwaukee, WI, USA). Subjects sat on a tilt chair at an angle of $45^{\circ}$. A variable region of interest programme that identified the ileocolonic junction was used to quantify appearance of radiolabels in the colon. Counts were expressed as per cent of total counts on a minute to minute basis, - that is, total counts were determined for each of the frames separately. This technique minimises any frame to frame variability that might be caused by movement of the subjects. ${ }^{99 \mathrm{~m}} \mathrm{Tc}$ - counts (determined at a $140 \mathrm{keV}(20) \%$ window) were corrected for down scatter from the "'In window (247 keV (20)\%). were at $0,10,20$, and $30 \mathrm{~cm}$ proximal to the terminal balloon ('distal sites') and at 60 and 70 $\mathrm{cm}$ ('proximal sites'). During the studies, the location of the tube was monitored fluoroscopically.

Manometry ports were perfused at $0 \cdot 1 \mathrm{ml} / \mathrm{min}$ with deionised water, using a pneumohydraulic capillary infusion system..$^{12}$ The perfused tubes were connected to pressure transducers (Statham-Gould, P-23, Statham Instruments, Inc, Halto Rey, Puerto Rico); outputs from the transducers were recorded on a Honeywell 1600 (Honeywell Technical Instruments, Inc,

TABLE I Ileocolonic transit of liquids and solids in healthy man *

\begin{tabular}{|c|c|c|c|c|c|c|c|c|}
\hline \multirow[b]{2}{*}{$\begin{array}{l}\text { Subject } \\
\text { no }\end{array}$} & \multicolumn{2}{|l|}{$\begin{array}{l}\text { Boluses } \\
(n)\end{array}$} & \multicolumn{2}{|c|}{$\begin{array}{l}\text { Transit effect of } \\
\text { boluses (\% of total } \\
\text { transport) }\end{array}$} & \multicolumn{2}{|l|}{$\begin{array}{l}T 15 \% \\
(\mathrm{~min})\end{array}$} & \multicolumn{2}{|l|}{$\begin{array}{l}T 50 \% \\
(\mathrm{~min})\end{array}$} \\
\hline & $\begin{array}{l}T c \\
\text { (liquids) }\end{array}$ & $\begin{array}{l}\text { In } \\
\text { (solids) }\end{array}$ & $\begin{array}{l}T c \\
\text { (liquids) }\end{array}$ & $\begin{array}{l}\text { In } \\
\text { (solids) }\end{array}$ & $\begin{array}{l}T c \\
\text { (liquids) }\end{array}$ & $\begin{array}{l}\text { In } \\
\text { (solids) }\end{array}$ & $\begin{array}{l}T c \\
\text { (liquids) }\end{array}$ & $\begin{array}{l}\text { In } \\
\text { (solids) }\end{array}$ \\
\hline $\begin{array}{l}1 \\
2 \\
3 \\
4 \\
5 \\
6 \\
\text { Mean }\end{array}$ & $\begin{array}{l}1 \\
2 \\
1 \\
1 \\
2 \\
1 \\
1 \cdot 3\end{array}$ & $\begin{array}{l}2 \\
2 \\
2 \\
1 \\
1 \\
3 \\
1 \cdot 8\end{array}$ & $\begin{array}{l}64 \\
88 \\
76 \\
74 \\
88 \\
55 \\
74\end{array}$ & $\begin{array}{l}82 \\
85 \\
65 \\
63 \\
50 \\
85 \\
72\end{array}$ & $\begin{array}{r}121 \\
188 \\
99 \\
216 \\
148 \\
105 \\
146\end{array}$ & $\begin{array}{r}128 \\
190 \\
95 \\
218 \\
133 \\
173 \\
140\end{array}$ & $\begin{array}{l}133 \\
196 \\
108 \\
221 \\
160 \\
174 \\
165\end{array}$ & $\begin{array}{l}200 \\
207 \\
112 \\
220 \\
155 \\
232 \\
188\end{array}$ \\
\hline
\end{tabular}

* Series I (infusion at $100 \mathrm{~cm}$ proximal to the ileocolonic junction)

\section{DATA ANALYSIS AND STATISTICS}

Counting was continued until at least $70 \%$ of one of the radiomarkers had reached the colon. Colonic filling was considered to be a 'bolus' when more than $10 \%$ of total counts moved into the colon within 10 minutes, as defined in previous studies..$^{78}$ 'Linear movement' was when ileocolonic transfer of counts was less than $10 \%$ counts/10 minutes. Times required for the colon to receive $15 \%$ of counts (T15\%) and for half filling (T50\%) were calculated separately for ${ }^{99 m} \mathrm{Tc}$ and ${ }^{~ ' I}$ In. Motility indices $\left(\log _{e}[\right.$ (sum of amplitudes $\times$ number of contractions) +1$]$ ) were calculated for the 10 minutes before, during and after ileocolonic transit of each bolus movement of the radiolabels. Motility tracings were visually analysed for previously described ${ }^{910}$ specific motility patterns - that is, migrating motor complexes, discrete clustered contractions and prolonged propagated contractions.

Colonic filling of ${ }^{99 \mathrm{~m}} \mathrm{Tc}$ and ${ }^{~ " ' I n ~ w e r e ~ c o m p a r e d ~}$ by Student's $t$ test. A p value less than 0.05 was considered as significant. In order to visualise any differential transit between solids and 

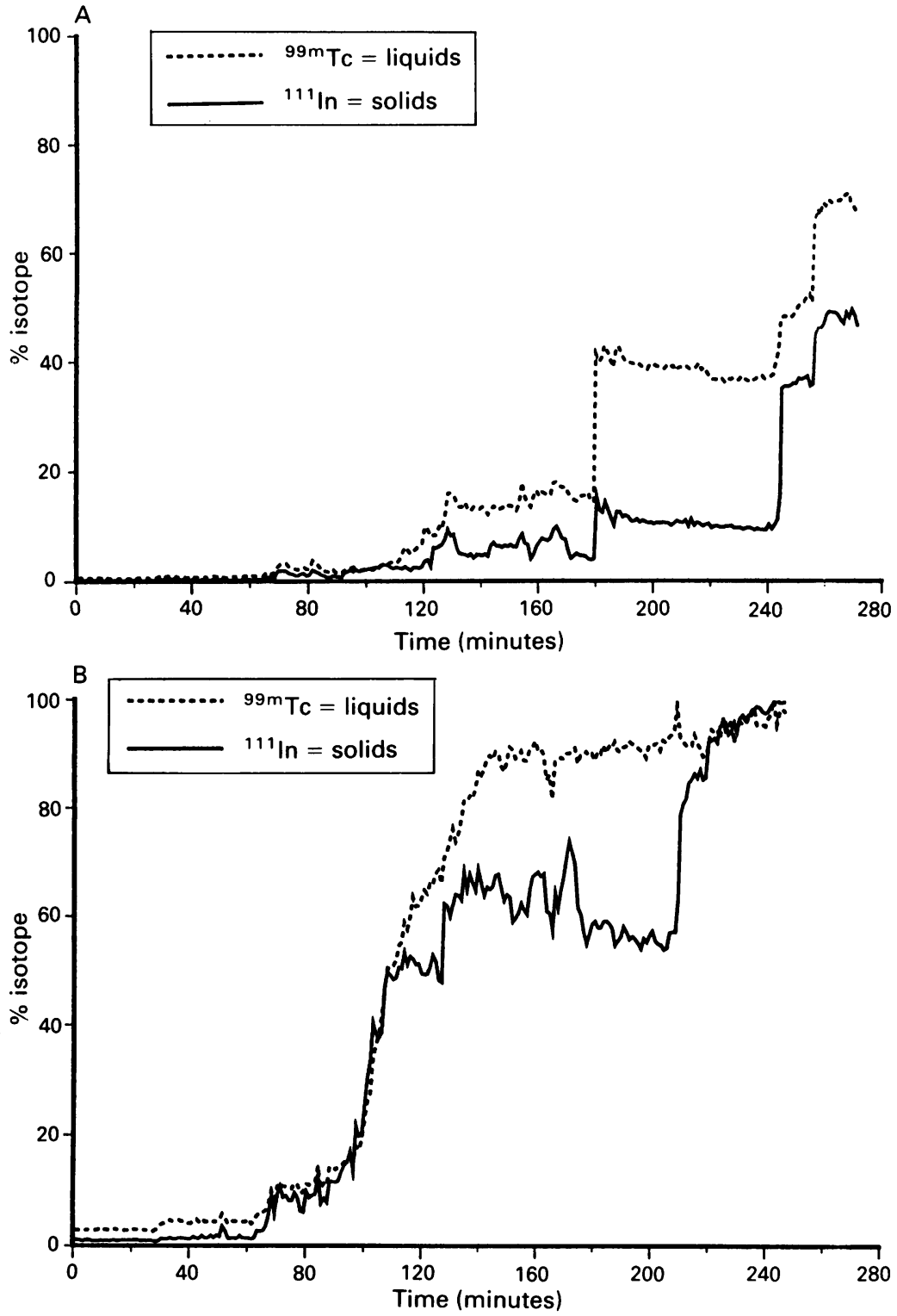

Figure 2A: Two examples of discriminant transit of liquids and solids when isotopes were infused $100 \mathrm{~cm}$ proximal to the ileocolonic junction. $(A)$ The first movement of counts into the colon (at $120 \mathrm{~min}$ ) did not meet the criteria of a bolus. The second bolus (at 180 minutes) moved solids and liquids to different degrees. $(B)$ The first bolus movement at 100 minutes transported liquids and solids to different degrees. A second bolus was recorded only for solids.

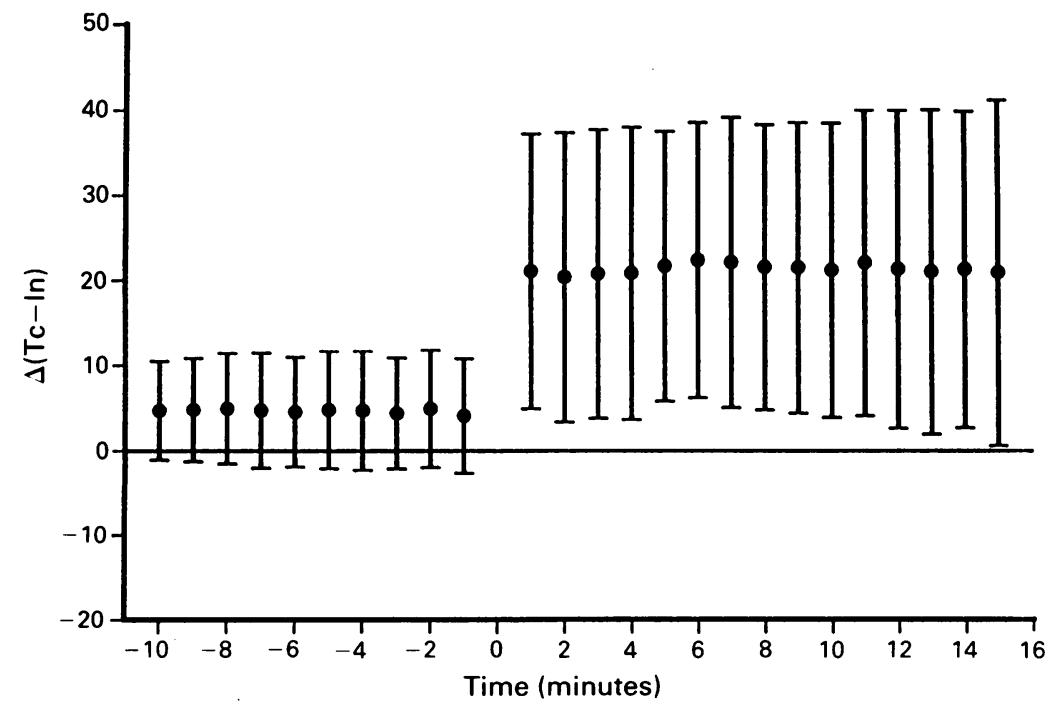

Figure 3: Mean differences between transit of liquids and solids ( $\triangle T c$ counts minus In counts, plus $95 \%$ confidence intervals) for 10 minutes before and 15 minutes after the first bolus movement. Markers were perfused $100 \mathrm{~cm}$ proximal to the ileocecal junction. After the bolus movement, a higher amount of technetium (liquid phase marker) was recorded from the colon; the liquid marker was transported more effectively than the solid marker. liquids, the difference between the proportion of colonic ${ }^{99 m} \mathrm{Tc}$ and ${ }^{11} \mathrm{In}$ counts during the 10 minutes before and the 15 minutes after the first bolus was expressed as the mean (95)\% confidence interval for each minute.

\section{Results}

As described previously ${ }^{73}$ in experiments that separately quantified the ileocolonic transit of liquids and solids, movement of both phases occurred largely as a series of boluses. In the present observations, bolus movements of ${ }^{\prime \prime} I n$ and ${ }^{99 m}$ Tc usually occurred together, but clear cut examples were observed when liquids and solids did not move simultaneously.

\section{INFUSION OF ISOTOPES INTO PROXIMAL ILEUM}

In the experiments of series I (six), the labels were infused approximately $100 \mathrm{~cm}$ proximal to the ileocolonic junction. Table I shows that by group analysis, the indices of colonic filling, $\mathrm{T} 15 \%$ and $\mathrm{T} 50 \%$, were not different for both isotopes $(p>0.05)$. Moreover, the number of boluses and the mean transit effect of boluses did not differ between the isotopes. There were dramatic examples, however, in which ${ }^{99 \mathrm{~m}} \mathrm{Tc}$ and ${ }^{11}$ In did not move together (see subjects \# 1 and 6 in Table I, and Figures 2A, B). Indeed, examples of discriminate movement of liquid and solid markers were seen in all of the six volunteers, and in all instances, Tc (liquid phase) moved more rapidly than did In (solid phase). Despite these examples of discriminant movements, however, the overall transit resulting from bolus transfers were not different between solids and liquids (Table I).

In Figure 3, the mean $((95) \%$ confidence intervals) of the differences between the total counts of ${ }^{99 \mathrm{~m}} \mathrm{Tc}$ and ${ }^{1 "} \mathrm{In}$ in the colon are plotted for each minute, from 10 minutes before to 15 minutes after passage of the first bolus across the ileocolonic junction. Before movement of the first bolus, the confidence intervals of these values overlap with the zero line, indicating that there was no significant difference between the transit of the liquid and solid markers. After the first bolus, the confidence limits do not intersect the zero line, showing a significant difference $(p<0.05)$ between the proportion of solids and liquids emptied by the bolus movement. The technetium counts (liquids) moved more freely.

\section{DISTAL INFUSION OF ISOTOPES}

Infusion of the solid-liquid 'meal' closer to the ileocolonic junction (series II, seven), led to both labels always being transported together into the colon. The times for 15 and $50 \%$ colonic filling of ${ }^{99 \mathrm{~m}} \mathrm{Tc}$ and "'In for each subject, which are shown in Table II, are not significantly different. The confidence limits for the difference between liquid and solid transit (Fig 4) overlapped with zero; thus, there was no significant difference between the mean transit of solids and liquids.

MOTILITY ASSOCIATED WITH BOLUS MOVEMENTS Our small 'meal' (75 kcal) did not always induce 


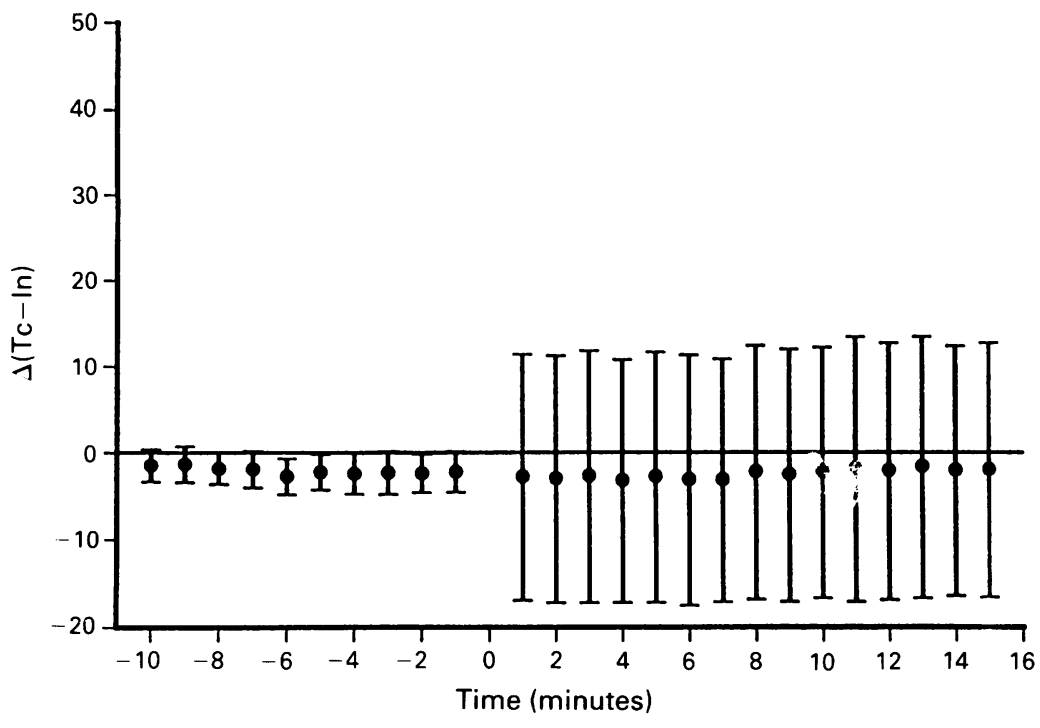

Figure 4: Mean differences between transit of liquids and solids before and after the first bolus movement of contents (see Figure 3 for details). When isotopes were infused into the distal ileum, solids and liquids appeared in the colon together.

a postprandial pattern of motility in the ileum. In series I, interdigestive cycles continued in four of our six subjects, in series II, fasting patterns of motility continued in five of seven persons. No particular patterns of ileal motility were observed regularly during bolus movements. Moreover, the motility index at the motility port in the distal ileum was not different for the 10 minutes before, during and after passage of the first bolus (mean $=10 \cdot 11,10 \cdot 45$, and $10 \cdot 29$, respectively). Motility indices at the other ports also were similar before, during and after the passage of boluses.

Qualitatively, ileocolonic boluses were observed during periods of low (Fig 5) and high motor activity in the ileum. In four of nine instances (in series I), an activity front (phase III of the interdigestive cycle) was associated with an ileocolonic bolus movement. Three of the four activity fronts discriminated fluids from solids, and fluids moved ahead of solids. Of five bolus movements not associated with phase 3 , four discriminated between the markers and one did not. No relationship between discrete clustered contractions ${ }^{910}$ and colonic filling was noted. No PPC's ${ }^{9}$ were observed in any study.

\section{Discussion}

These experiments were designed to test the

TABLE II Ileocolonic transit of liquids and solids in healthy man ${ }^{\star}$

\begin{tabular}{|c|c|c|c|c|c|c|c|c|}
\hline \multirow[b]{2}{*}{$\begin{array}{l}\text { Subject } \\
\text { no }\end{array}$} & \multicolumn{2}{|l|}{$\begin{array}{l}\text { Boluses } \\
(n)\end{array}$} & \multicolumn{2}{|c|}{$\begin{array}{l}\text { Transit effect of } \\
\text { boluses }(\% \text { of total } \\
\text { transport) }\end{array}$} & \multicolumn{2}{|l|}{$\begin{array}{l}T 15 \% \\
(\min )\end{array}$} & \multicolumn{2}{|l|}{$\begin{array}{l}T 50 \% \\
(\mathrm{~min})\end{array}$} \\
\hline & $\begin{array}{l}\text { Tc } \\
\text { (liquids) }\end{array}$ & $\begin{array}{l}\text { In } \\
\text { (solids) }\end{array}$ & $\begin{array}{l}T c \\
\text { (liquids) }\end{array}$ & $\begin{array}{l}\text { In } \\
\text { (solids) }\end{array}$ & $\begin{array}{l}T c \\
\text { (liquids) }\end{array}$ & $\begin{array}{l}\text { In } \\
\text { (solids) }\end{array}$ & $\begin{array}{l}T c \\
\text { (liquids) }\end{array}$ & $\begin{array}{l}\text { In } \\
\text { (solids) }\end{array}$ \\
\hline 7 & 1 & 2 & 48 & 56 & 16 & 9 & 102 & 71 \\
\hline 8 & 2 & 3 & 64 & 75 & 66 & 62 & 104 & 90 \\
\hline 9 & 1 & 2 & 65 & 80 & 140 & 91 & 160 & 160 \\
\hline 10 & 1 & 3 & 59 & 81 & 65 & 67 & 77 & 93 \\
\hline 11 & 2 & 2 & 86 & 63 & 95 & 91 & 126 & 117 \\
\hline 12 & 1 & 2 & 74 & 98 & 85 & 85 & 130 & 130 \\
\hline 13 & 1 & 1 & 95 & 94 & 211 & 211 & 224 & 221 \\
\hline Mean & $1 \cdot 3$ & $2 \cdot 1$ & 70 & 78 & 97 & 88 & 93 & 126 \\
\hline
\end{tabular}

^Series II (infusion at less than $50 \mathrm{~cm}$ from the ileocolonic sphincter) hypothesis that the ileocolonic junction, which features bolus filling of the colon in health and disease, ${ }^{6-813}$ would not differentiate between solids and liquids. We reasoned that the propulsive motor patterns of the ileum ${ }^{910}$ would move solids and liquids into the caecum together. We were initially surprised to find that the ileum was able, on occasions, to separate liquids and solids as in series I. Thus, although overall mean transits of solids and liquids were not significantly different in series I experiments, there were clear-cut examples (Figs 2A, B) in which solids and liquids moved separately. Moreover, as shown in Figure 3 there were group differences between liquid and solid transit after the first bolus movement. Although this finding suggested that the ileocolonic segment was able to discriminate solids from liquids, we wondered about other mechanisms.

Thus, the 'meals' were instilled at a point closer to the ileocolonic junction in the series II experiments, as we reasoned that the more proximal infusions may have allowed solids and liquids to have been prepackaged, by differential transit in the ileum. In this way, the labels may have arrived differentially at the ileocolonic junction. When they were instilled closer to the ileocolonic junction, solids and liquids always moved together. Our general interpretation is that the proximal ileum is able to discriminate between solids and liquids, but that the region immediately adjacent to the ileocolonic junction does not. We added Veegum to our infusates to prevent the resin pellets from sedimenting in the infusion tube. Although the physical state of chyme in the intact ileum is not known, it is presumed to have some viscosity. Thus, our infusates may have mimicked ileal contents better than would have a non-viscous fluid. Moreover, as we found examples of discriminant transit of solids and liquids in all subjects (series 1), the presence of Veegum seems unlikely to have had major physical consequences.

Bolus movements were defined as the transfer of 10 or more per cent of total counts (solid or liquid phase markers) within a period of 10 minutes. Spiller first showed that colonic filling of a liquid phase marker occurred by bolus movements ${ }^{613}$ and his findings were confirmed subsequently for small solid particles. ${ }^{78}$ The concept that the most distal ileum stores dietary residue and then empties intermittently is not new; Hurst ${ }^{14}$ likened the ileocolonic junction to an 'intestinal stomach' which stored residue and then emptied into the colon. Moreover, we described earlier the storage of dietary residue, in the terminal ileum until a second meal prompted colonic filling. ${ }^{15}$

In a substantive study of solid-liquid transit along the human small bowel, Malagelada and colleagues $^{5}$ described differences in gastric emptying of radiolabelled cellulose fibres and a liquid phase marker. After separation of the solid and liquid phases at the gastric level, liquids and solids then moved along the small bowel at equal rates. The present data suggest that, at least in the ileum, solids and liquids may again be separated.

We had hoped to stimulate a 'fed pattern' of motility in the distal small bowel by instilling a 


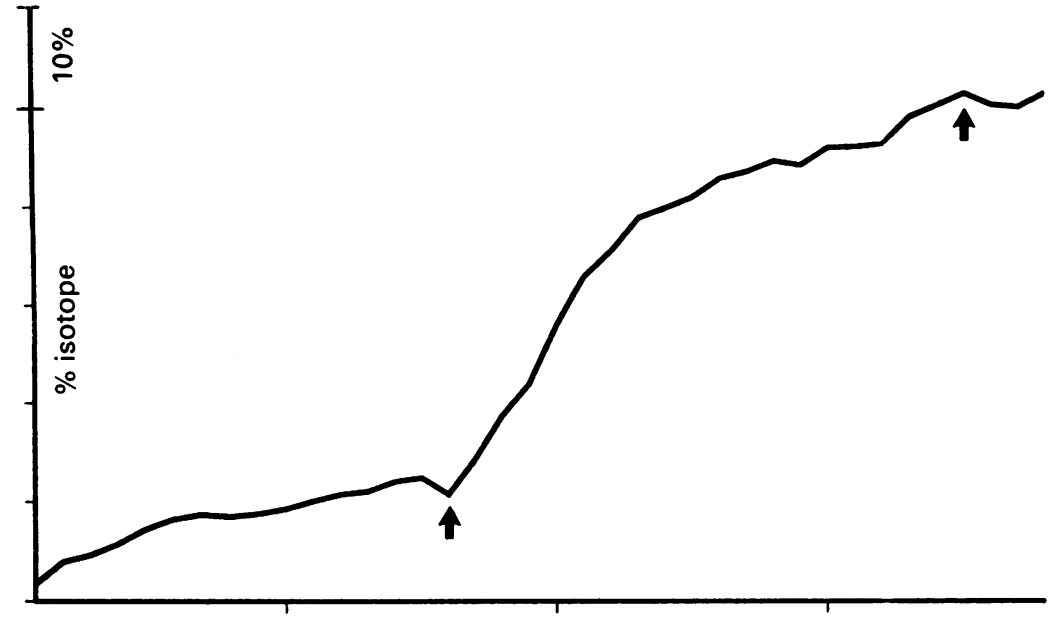

10 minutes

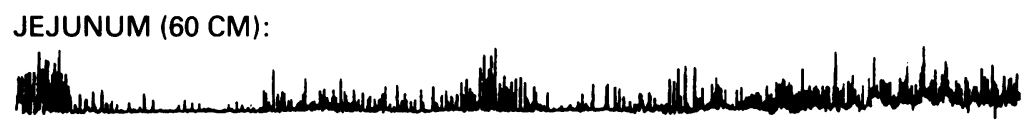

JEJUNUM (50 CM):

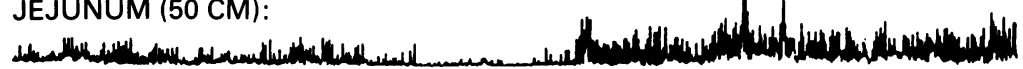

ILEUM (20 CM):
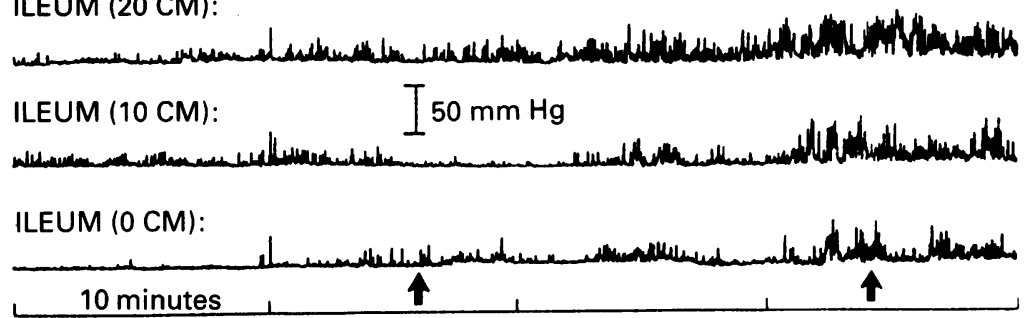

Figure 5: This example of a bolus movement of isotope from ileum to colon (approximately $40 \%$ of counts in the liquid phase were moved in the 20 minute period demarcated by the arrows) that was associated with a low ileal motility index.

small amount of nutrient. The calorie content was low $(75 \mathrm{kcal})$ and we were only partially successful, because fasting motor patterns were preserved in most experiments. The fasting cycle continued in more than half of our volunteers, although phase 3 of the migrating motor complex does not often reach the human ileum. ${ }^{10}$ Thus, this makes the association between ileal motor patterns and bolus transit more difficult to analyse. Interdigestive patterns (including phase 3) were present in some subjects, but not in others.

Our general conclusion is a negative one, in that no particular motor pattern was associated with the bolus transfer of liquids or solids, or of both. This is in accordance with previous findings where no discrete motor pattern could be related to ileocolonic transport of liquids. ${ }^{13}$

Supported in part by grant \#DK32121 from the National Institutes of Health, Bethesda, MD

1 Meyer JH. Motility of the stomach and gastroduodena junction. In: Johnson LR, eds. Physiology of the gastrointestinal tract. 2nd ed. New York, Raven Press, 1987: 61329.

2 Barreiro MA, McKenna RD, Beck IT. Determination of transit in the human jejunum by the single-injection indicator-dilution technique. Am $\mathcal{F}$ Dig Dis 1968; 13: 222 33.

3 Kerlin P, Zinsmeister A, Phillips SF. Relationship of motility to flow of contents in the human small intestine. Gastroenterology 1982; 82: 701-6.

4 Sarr MG, Kelly KA. Patterns of movement of liquids and solids through canine jejunum. Am 7 Physiol 1980; 239: G497-503.

5 Malagelada J-R, Robertson JS, Brown ML, Remington M Duenes JA, Thomforde GM, et al. Intestinal transit of solid and liquid components of a meal in health. Gastroenterology 1984; 87: 1255-63.

6 Spiller RC, Brown ML, Phillips SF, Azpiroz F. Scintigraphic measurements of canine ileocolonic transit. Direct and indirect effects of eating. Gastroenterology 1986; 91: 1213-20.

7 Camilleri M, Colemont LJ, Phillips SF, Brown ML, Thomforde GM, Chapman N, et al. Human gastric emptying and colonic filling of solids characterized by a new method Am F Physiol 1989; 257: G284-90.

8 Greydanus MP, Camilleri M, Colemont LJ, Phillips SF Brown ML, Thomforde GM. Ileocolonic transfer of solid chyme in small intestinal neuropathies and myopathies. Gastroenterology 1990; 99: 158-64.

9 Quigley EMM, Borody TJ, Phillips SF, Wienbeck M, Tucker RL, Haddad A. Motility of the terminal ileum and ileocecal sphincter in healthy humans. Gastroenterology 1984; 87: 85766 .

10 Kellow JE, Borody TJ, Phillips SF, Tucker RL, Haddad AC. Human interdigestive motility: variations in patterns from Human interdigestive motility: variations in patterns

11 Kerlin P, Tucker R, Phillips SF. Rapid intubation of the ileocolonic region in man. Aust $N$ Z F Med 1983; 13: 591-2.

12 Kerlin P, Phillips SF. Variability of motility of the ileum and jejunum in healthy humans. Gastroenterology 1982; 82: 694 700.

13 Spiller RC, Brown ML, Phillips SF. Empyting of termina ileum in intact humans. Influence of meal residue and ilea motility Gastroenterology 1987; 92: 724-9.

14 Hurst AF. In: Discussion on the function of the sympathetic nervous system. Proc $R$ Soc Med 1931-32; 25: 1597-99.

15 Kerlin P, Phillips SF. Differential transit of liquids and solid residue through the human ileum. Am $\mathcal{F}$ Physiol 1983; 245: residue 